\title{
Comparision of the Bearing Rings Deformation after Heat Treatment
}

\author{
Dana Stancekova ${ }^{1}$, Anna Rudawska ${ }^{2}$, Jozef Mrázik ${ }^{1}$, Filip Turian ${ }^{1}$ \\ ${ }^{1}$ University of Zilina, Faculty of Mechanical Engineering, Univerzitna 1, 010 26, Zilina, Slovak Republic, \\ dana.stancekova@fstroj.uniza.sk, \\ ${ }^{2}$ Lublin University of Technology, Faculty of Mechanical Engineering, Nadbystrzycka 36, 20-618 Lublin, Poland, \\ a.rudawska@pollub.pl
}

This thesis deals with deformations originating from heat treatment of the bearing metals. This is about the comparison of the heat treatment by rotating method in which the parts are feeded individually into the rotating device and heat treated on hardening equipment in continuous way with high capacitive power. After the heat treatment it follows the operations of the grinding of the faces and diameters of the bearing rings. After the hardening we take into account two parameters, which may be mostly affected by hardening process namely: flatness of the faces (cradle) and outer diameter ovality. Each of such deviations has got adverse influence during the grinding, therefore the hardening technology is in most cases focused on elimination of this problem. The results of the heat treatment with higher deformations were confronted with values achieved by simulation software SYSWELD used for heat-metalurgical analysis.

Keywords: hardening, bearing ring, deformation, ovality, microstructure

\section{Introduction}

Parts of power trains, like gear wheels and bearing rings, are subject of increasingly strong requirements, with regard to load transmission, noise reduction and weight [1]. These requirements can only be met if a high accuracy of the workpieces' geometry is retained $[2,3]$.

In order for rolling bearings to fulfill their function, the individual parts must have suitable mechanical properties. These properties are obtained by quenching and low-temperature tempering. Quenching should give the bearing steel the required hardness and tempering should reduce inner stresses and reduce the brittleness of the quenched bearing steel. The heat treatment determines the final properties of the individual parts of the rolling bearings and has a decisive influence on their function to a large extent. The required mechanical properties are determined in particular by the state of the initial microstructure and the inner stresses before quenching, the uniformity of the heating to the austenitization temperature, the austenitization conditions and the cooling from the austenitization temperature. Because the heating and cooling rates of the surface and the core are always different, the inner stress during quenching increases. The individual parts are subsequently deformed $[4,5,6,7]$.

The production line of bearing rings consists of forging, cutting, heat treatment and machining. The most common failure of the bearing rings is a geometrical distortion called ovality. To avoid such failures, it is essential to be aware of the evolution of the residual stress state of the semi-products during the whole manufacturing line. $[8,9,10]$.

Cesh and colleagues [11] focused on the effects of residual stresses, which have accumulated in the bearing rings during production and heat treatment. They interpreted the effects of the heat treatment failures such as decarburisation, carburation, and oxidation. The effect of carburisation and decarburisation in the near surface region during the heat treatment were observed by microstructure analysis and the change in the full width at half maximum values (FWHM) of the diffraction peaks used for the stress calculations.

The task of this research work is to analyze the deformations caused by two different methods of heat treatment in the selected type spectrum and to compare this state with the simulation software SYSWELD suitable for simulation of heat treatment.

\section{Rotary quenching}

The first technological test was performed on a quenching device in a rotary manner (quenching line LOI), where the parts were fed to the input conveyor at regular intervals.

By passing through the individual zones, the parts were heated to the austenitization temperature. Rapid or uneven heating to this temperature creates thermal stresses that can be removed by reducing or prolonging the heating. However, the largest deformations occur during cooling from the austenitization temperature. These deformations are reduced by a device that simultaneously fixes, balances and at the same 
time rotates the parts during quenching. The whole process takes place in a tank with quenching oil, the temperature of which is adjustable. Another operation after the parts have become quenched is a magnatest check. It is a non-destructive test of material properties such as hardness or depth of the quenched layer. This check is evaluated on the basis of calibration by means of calibration samples. After the check by magnatest, the parts pass through a tempering furnace and a preservative device.

Rotary quenching can ensure that the deformations that accompany the various types of heat treatment are as small as possible and meet the conditions imposed by the following operations. The disadvantage of this method is low efficiency and high quenching costs; therefore, this method is not suitable for heat treatment of parts with a high annual requirement.

Bearing rings (with dimensions - outer diameter $80.3 \mathrm{~mm}$, inner diameter $65.51 \mathrm{~mm}$, height $21.2 \mathrm{~mm}$ ) made of 100Cr MnSi6-4 steel, marking according to EN ISO - steel with increased hardenability, which can be achieved by adding manganese, were used for the technological test by rotary quenching.

The austenitization temperatures of this steel during quenching are $830-870{ }^{\circ} \mathrm{C}$, the tempering temperature range is most often $150-180^{\circ} \mathrm{C}$. In our case, the parts were tempered at a temperature of $190{ }^{\circ} \mathrm{C}$. The cooling medium was quenching oil. Hardness after quenching min $64 \mathrm{HRC}$ and hardness after tempering $59+4$ HRC.

The parts were taken from normal production, then before quenching they were measured to the parameters that are most influenced by heat treatment, Fig. 1 . The average ovality of the rings was found to be $0.014 \mathrm{~mm}$ by measurement.

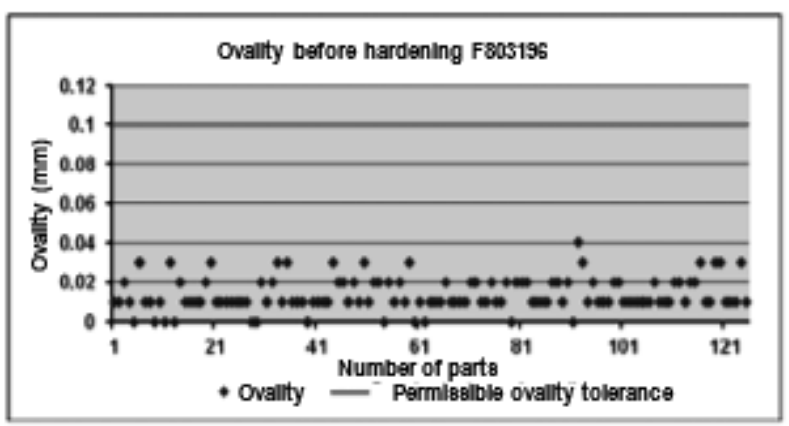

Fig. 1 The ovality of parts before quenching on LOI

\section{The values of setting of quenching line $\mathrm{LOI}$}

The values of setting of quenching line correspond to the values recommended by standars EN 10025 for quenching bearing steel 100CrMnSi6-4, Tab. 1 .

Tab. 1 The values of setting of quenching line LOI for heat treated samples in a rotary manner: Type: AU F - 803196 Quenching furnace - Temperature $\left[{ }^{\circ} \mathrm{C}\right]$

\begin{tabular}{|ccc|}
\hline Zone 1 & Zone 2 & Zone 3 \\
\hline $850+10 /-50$ & $850+/-15$ & $840+/-10$ \\
\hline Continuous time [min.] & $21+/-2$ & \\
& & \\
Carbon level [\%] & Front space of furnace & Back space of furnace \\
& $0.8+/-0.2$ & $0.8+/-0.2$
\end{tabular}

Tempering furnace - Temperature $\left[{ }^{\circ} \mathrm{C}\right]$

$\begin{array}{ccc}\text { Zone } 1 & \text { Zone } 2 & \text { Zone } 3 \\ 190+/-10 & 190+/-10 & 190+/-10\end{array}$

\section{Continuous time $[\mathrm{min}] \quad 120+/-5$}

Temperature of quenching oil $\left[{ }^{\circ} \mathrm{C}\right] \quad 45+/-15$

Feeding time [sec.]

Marquench 600 quenching oil was used to cool the parts from the austenitization temperature. In addition to the cooling capacity of the oil, the austenitization temperature of the quenched part, the desired temperature of the quenching bath, the shape and size of the
$44+/-2$

quenched part, the method and intensity of circulation of the quenching bath are taken into account when selecting the quenching oil. Oxidation stability and volatility are important factors, and these factors have a decisive influence on the life of the oil. 


\section{Quenching on a continuous line}

This method of quenching is suitable for largescale production. The parts are transported through the working space of the furnace through individual zones on a belt conveyor. The actual arrangement of parts is very important. This is ensured by an adjustable dosing device, which ensures a smooth supply of parts to the working belt of the quenching device. After heating to the austenitization temperature, the parts are immersed in quenching oil, from which they are subsequently conveyed by a conveyor to a washing and drying device. By passing the parts through the tempering furnace, we achieve the required hardness, changes in inner stress and also reduce the brittleness of quenched bearing steel. The last operation after heat treatment is the preservation of parts.

The same bearing rings made of 100Cr MnSi6-4 steel were used for the second technological test of quenching on a continuous furnace. It is steel with increased hardenability, which we achieve by adding manganese. The austenitization temperatures of this steel during quenching are again $830-870^{\circ} \mathrm{C}$, the tempering temperature range is most often $150-180^{\circ} \mathrm{C}$. The tempering temperature of $190{ }^{\circ} \mathrm{C}$ was used again for tempering. The cooling medium was quenching oil.

The parts were taken from standard production, the necessary measurements were performed on a talyrond 130 measuring instrument, according to standard S 241011-2, which we evaluated in graphical form. No deviation from the specified turning tolerances was noted. The parts were then marked and heat treated with other products. The average ovality of the rings was found to be $0.024 \mathrm{~mm}$ by measurement, Fig. 2.

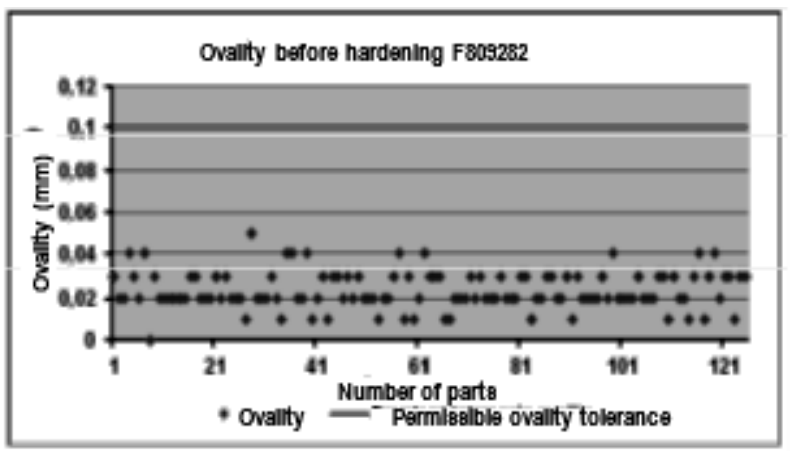

Fig. 2 The ovality of parts before quenching on Kohnle 900

\section{The values of setting of quenching line Kohnle 900}

The values of setting of quenching line correspond to the values recommended by standars EN 10025 for quenching bearing steel 100CrMnSi6-4, Tab. 2 .

Tab. 2The values of setting of quenching line Kohnle 900 for heat treated samples in a continuous manner -Type: AU F-809282 Quenching furnace - Temperature $\left[{ }^{\circ} \mathrm{C}\right]$

\begin{tabular}{|c|c|c|c|c|}
\hline Zone 1 & Zone 2 & Zone 3 & Zone 4 & Zone 5 \\
\hline $850+10 /-30$ & $850+/-15$ & $840+/-10$ & $840+/-10$ & $840+/-10$ \\
\hline Continuou & & $5+3 /-2$ & & \\
\hline \multirow{2}{*}{ Carbon level $[\%]$} & Front sp & rnace & \multicolumn{2}{|c|}{ Back space of furnace } \\
\hline & \multicolumn{2}{|c|}{$0.7+0.2 /-0.1$} & \multicolumn{2}{|c|}{$0.7+0.2 /-0.1$} \\
\hline
\end{tabular}

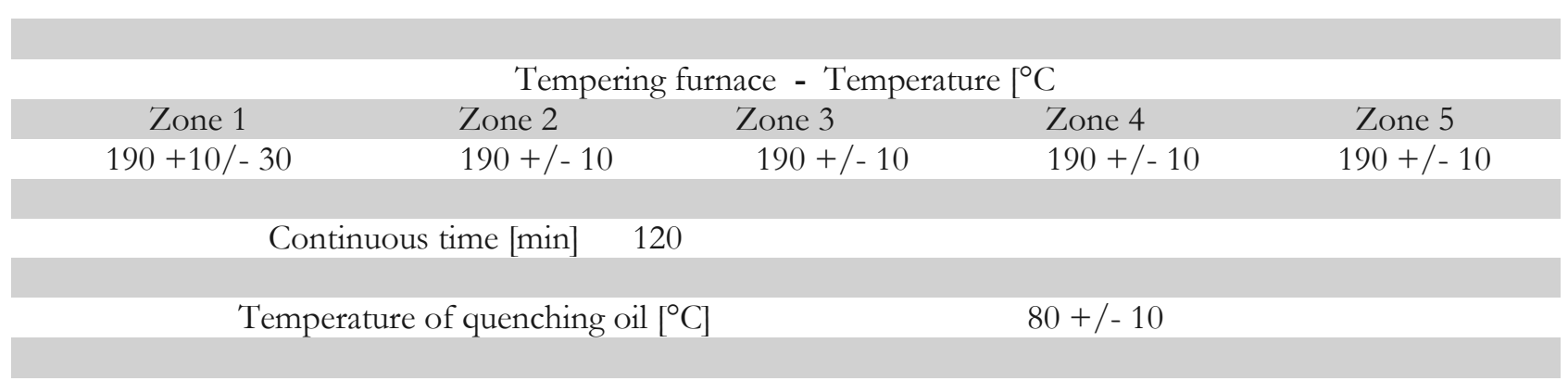

\section{Continuous time $\left[\mathrm{m} \cdot \mathrm{h}^{-1}\right]$}

For cooling of parts from the austenitization temperature was used quenching oil Marquench 600, which properties are same than during quenching on the rotary line.

\section{Hardness tests}

After quenching, a Rockwell hardness test was performed on the parts. The hardness can be determined

$$
1.1+/-0.1
$$

using a non-motorized analog hardness tester. In our case, the Rockwell hardness value was determined on a digital hardness tester with computer support, Tab. 3.

The hardness is measured at the front of the bearing ring. The prescribed hardness of $59+4 \mathrm{HRC}$ was observed for both types of hardening. In the case of a lower hardness is growing toughness, but we also 
dropping dynamic load, resulting in reduced bearing life. The correct hardness after hardening guarantees us not only the required properties of the bearing rings, but also good machinability.

Tab. 3 Measured hardness values

\begin{tabular}{|c|c|c|c|c|c|c|c|}
\hline \multicolumn{8}{|c|}{ HRC } \\
\hline \multicolumn{4}{|c|}{ Quenching LOI } & \multicolumn{4}{|c|}{ Quenching Kobnle } \\
\hline 59.55 & 59.25 & 59.05 & 59.90 & 59.20 & 60.25 & 59.05 & 59.95 \\
\hline 60.00 & 59.85 & 59.45 & 60.05 & 59.95 & 59.95 & 59.35 & 59.80 \\
\hline \multicolumn{8}{|c|}{ Mean hardness value } \\
\hline \multicolumn{4}{|c|}{ 59.64 HRC } & \multicolumn{4}{|c|}{ 59.69 HRC } \\
\hline
\end{tabular}

\section{Microstructure of bearing rings}

The samples needed to make the microstructure were taken from quenched rings. The prepared samples were analyzed for microstructure, which was performed on a Neophot 2 microscope.

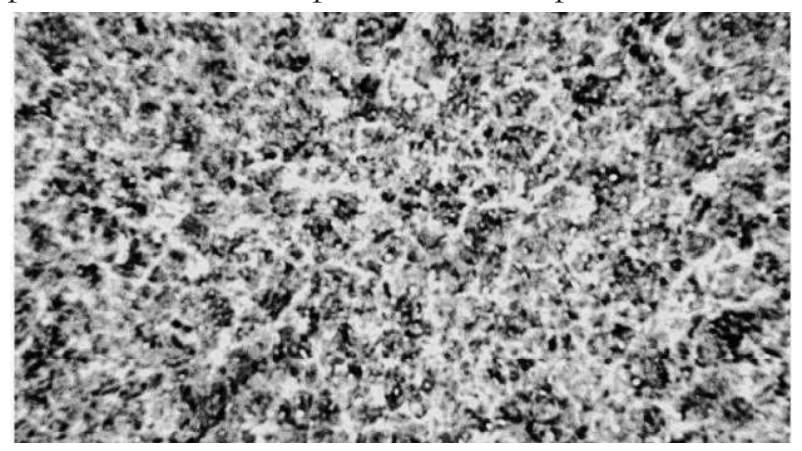

Fig. 3 Microstructure of bearing rings F 803196 after quenching and tempering Etched by. $2 \%$ Nital, $3 \times 10$ sec, room. $500 x$

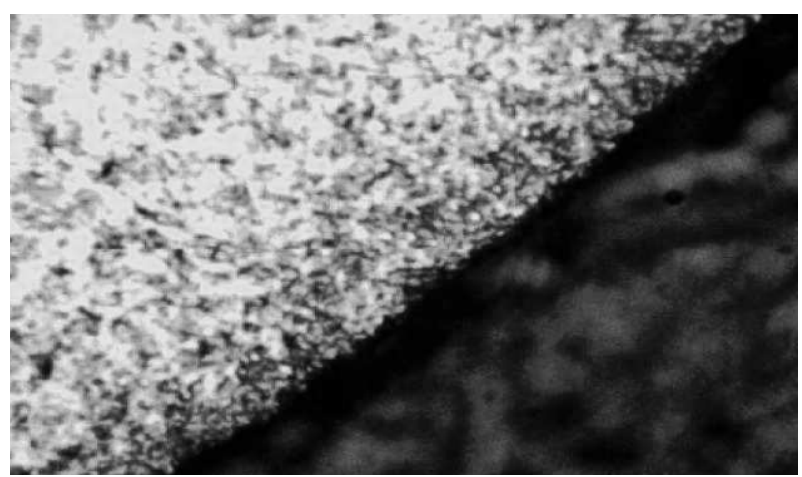

Fig. 4 Microstructure of bearing rings F 803196 after quenching and tempering - highlighting the difference in structure at the circumference of the ring and at the core of the ring, zoom. $500 x$

The final microstructure after quenching and tempering is, as in the case of other super-eutectoid steels, formed by tempered martensite, carbides and a small amount of residual austenite. Figures 3 and 4 show the microstructures of bearing rings $F$ 803196, which have been rotationally quenched and subsequently tempered. Figure 4 shows a structure consisting of evenly distributed carbides (dark spots) and tempered martensite with residual austenite (light yellow fields). The core of these rings has a lower through-hardening than in the case of the ring $\mathrm{F} 809282$, the hardness on the surface being the same in both cases. However, the zone of the highest through-hardening is smaller, which is clearly seen in Figure 5. The circumference had a higher cooling intensity, ie a higher cooling rate and the resulting higher hardening and hardness.

The figure 5 representation structure of quenching ring F 809282 on the quenching line Kohnle. The structure after quenching and tempering is formed by evenly distributed carbides (dark spots) and tempered martensite with residual austenite (light yellow fields).

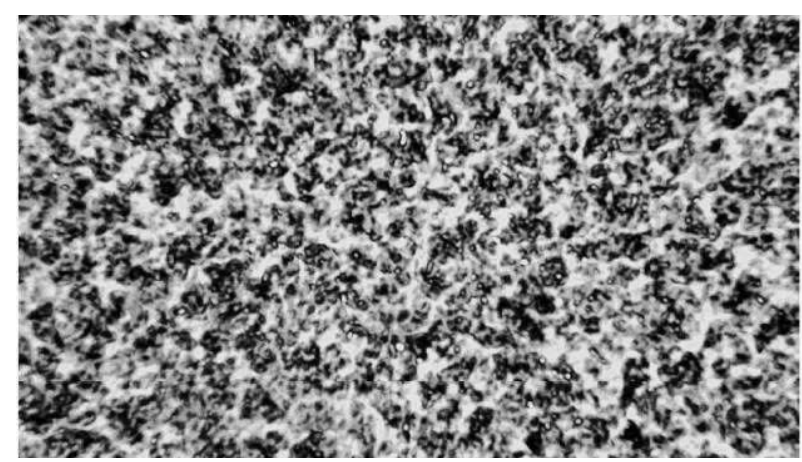

Fig. 5 Microstructure of bearing ring $F 809282$ after quenching and tempering Etched by. 2\% Nital, $3 \times 10$ sec, zoom. $500 x$

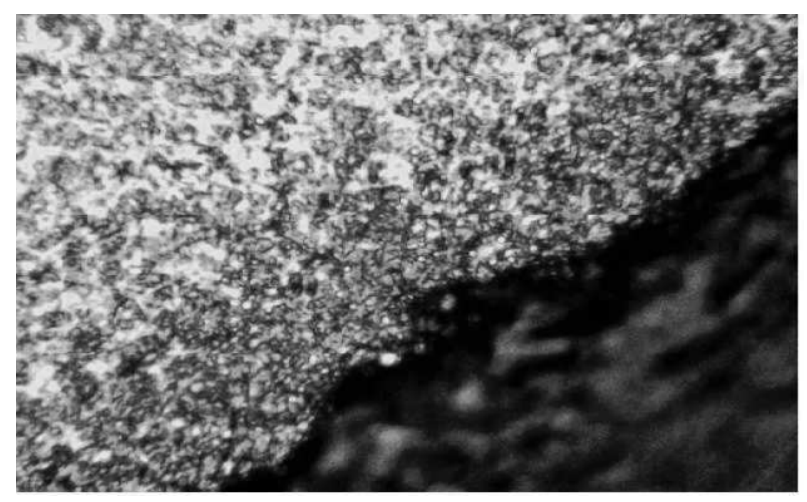

Fig. 6 Microstructure of bearing ring F 809282 after quenching and tempering - highlighting the difference in structure at the circumference of the ring and at the core of the ring, zoom. $500 x$

\subsection{Comparison of ovality of quenched samples}

By quenching on the LOI quenching line, the required ovality parameters were achieved, which we 
achieved using a fixing device. Incorrect settings of this device, e.g. poor fixation, or incorrectly set speed, can have the exact opposite effect. Due to dirt, parts may not fit properly in the product, in most cases they are metal chips after soft operations.

We achieved a maximum ovality of $0.08 \mathrm{~mm}$ by rotary quenching, the average achieved ovality after quenching increased to $0.032 \mathrm{~mm}$, this ovality did not change by tempering. The ovality values are recorded in Figure 7.

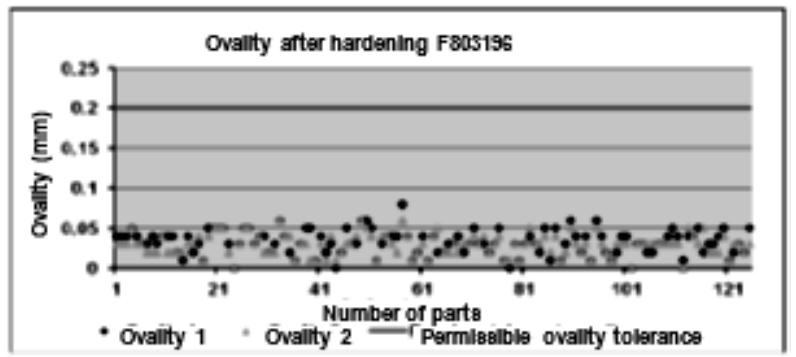

Fig. 7 The ovality of parts after quenching on LOI

The opposite case occurred during quenching on the Kohnle quenching device. Deformations increased several times. The highest ovality of $0.05 \mathrm{~mm}$ was measured before quenching, after quenching this ovality increased to $0.3 \mathrm{~mm}$ Figure 8 . From the results so far, it is not possible to unambiguously determine the origin of the resulting deformation after quenching on the Kohnle quenching device. One of the reasons for the deformations may be the different wall thicknesses. Further deformations are caused by stresses created before quenching. The method of heating and cooling has a great influence on the quenching conditions, last but not least, it is a method of immersing the ring in quenching oil.

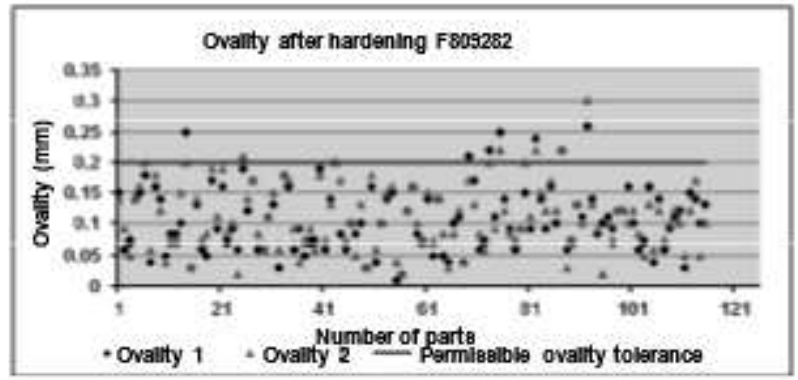

Fig. 8 The ovality of parts after quenching on Kobnle 900

\section{Simulation software for heat treatment}

Based on the above assumptions and regularities, it is clear that the primary requirement for the technological process of heat treatment is its rationality, ie. that the required properties will be achieved without unnecessarily increasing costs and time losses $[12,13]$.

Simulation software is a modern tool that allows you to capture potential technology shortcomings in a timely manner and minimize them or completely eliminate them well in advance. There are several simulation software for the field of heat treatment, in the region of Central Europe, SYSWELD from the manufacturer ESI Group and DEFORM HT from Scientific Forming Technologies Corporation are currently becoming known [14].

All the above conditions, as well as data from the technological process, were used in the simulation software for heat treatment. The output values from this simulation software will be used for comparison with the values of continuous quenching.

The actual calculation in the SYSWELD program is divided into two stages, thermal-metallurgical and mechanical. Thermal-metallurgical analysis solves the calculation of non-stationary temperature fields, phase transformations, structure hardness, or austenitic grain size. Mechanical analysis follows the thermo-metallurgical analysis and enables the calculation of time courses of individual components of the stress tensor, values of main stresses, analysis of the spatial stress state according to $\mathrm{HMH}$ theory and Tresco analysis of shear stresses [15].

SYSWELD simulation software is finite element method (FEM) software. In addition to simulating various welding technologies, it also allows to simulate volumetric and surface heat treatment technologies, and the carburization process [14].

The input for the simulation is a model formed by a $2 \mathrm{D}$ or $3 \mathrm{D}$ network of points, which must always contain the so-called network part (2D or 3D) and heat transfer part. The output of the simulation is a file containing: cooling process, phase change process, hardness values, mechanical characteristics (circumferential and residual stresses, deformations).

The simulation (calculation) is based on the measured data, which form an internal database. These are specific to each material, depending on the chemical composition of the material. The basis for the simulation of files of type $\mathrm{a}$ and $\mathrm{b}$ in the case of steels is the ARA diagram [14].

\section{Simulation results}

We used the HT Advisor application of the SYSWELD software to simulate the heat treatment. The simulation was focused on the analysis of deformations caused by continuous quenching on the Kohnle 900 quenching line. The simulation confirmed the stresses and associated deformation, especially ovality.

The simulation results focused on HV hardness (according to Vickers) were compared with the values measured on a digital hardness tester. By default, the hardness after heat treatment is measured by the HRC method (according to Rockwell). For comparison, it was necessary to perform these measurements by the 
same method as in the simulation. Measurements were performed at three locations in Figure 9 with the maximum possible number of punctures.

The results shown in Table 4 show us the highest hardness in the middle of the ring (orbit), in the place with the smallest cross-section. The resulting hardness value $\mathrm{HV}$ obtained by measuring on a hardness tester is comparable to the hardness value obtained in the simulation.
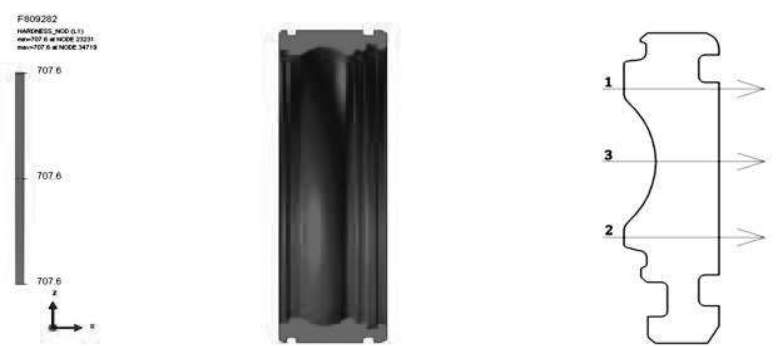

Fig. 9 a) The simulation result of hardness according to Vickers $H V$, b) The location of hardness measuring

Tab. 4 Measured values on a Vickers $H V$ hardness tester in three lines of measurement

\begin{tabular}{|l|c|c|c|c|c|c|c|c|c|}
\hline & 1. & 2. & 3. & 4. & 5. & 6. & 7. & 8. & mean \\
\hline Line 1 & 736.1 & 720.1 & 713.9 & 707.3 & 712.5 & 721.6 & 720.2 & 727.7 & 720 \\
\hline Line 2 & 743.1 & 745.3 & 723.1 & 731.7 & 742.3 & 737.5 & 746.8 & 747.1 & 740 \\
\hline Line 3 & 755.1 & 746.4 & 736.1 & 742.7 & 755.1 & 743.6 & 749.2 & 746.6 & 747 \\
\hline
\end{tabular}

The results of the heat treatment simulation focused on the deformations of the rings and the associated ovality are shown in Figure $10 \mathrm{a}$, b. The snaps clearly showed us the origin of these deformations. The value on the scale shows us the amount of deformation in $\mathrm{mm}$. These values can be compared with the values measured after heat treatment on a continuous device. Another important indication is the place of deformation. A deeper analysis revealed greater ovality on the side with a smaller cross-section.
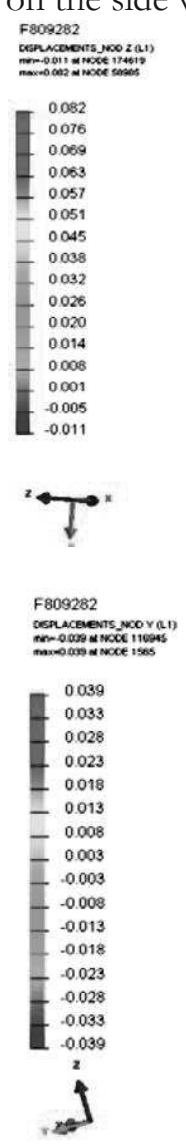

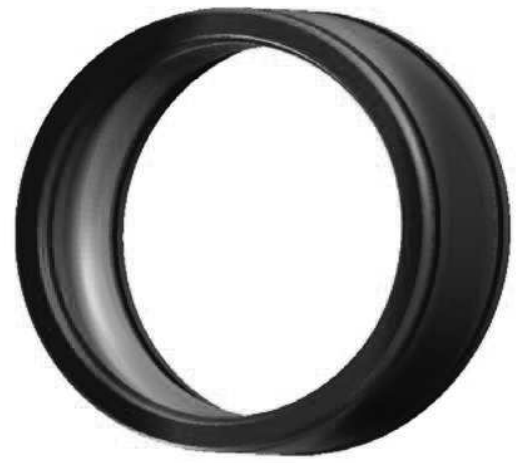

a)

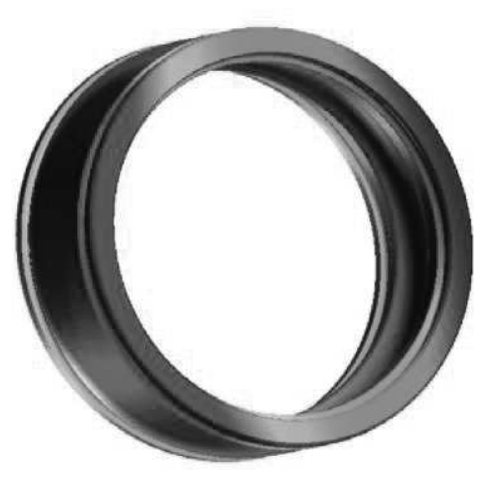

b)
Fig 10 The simulation result focus on deformation a) the ovality in the $Z$ axis, b) the ovality in the $Y$ axis
The thermal-metallurgical analysis of the SYSWELD software has clearly pointed out the deformations that can occur during heat treatment in a continuous manner. The results from real measurements and simulations are comparable and it is possible to work with these values further.

\section{Conclusion}

The aim of the research was to analyze the deformations of the bearing rings after the final heat treatment.

The individual tests performed clearly showed us the effect of heat treatment on the deformations of the bearing rings. Although it is necessary to point out the various stresses that are introduced into the material already during processing in soft turning or rolling operations. In many cases, it is the material itself that plays a significant role in the problems that arise in operations following heat treatment.

The first rotary test showed us the benefits of this quenching. The method of feeding parts in individual tracks with a certain distance to the fixing device, subsequent clamping and rotation of parts ensures minimal deformations. In this case, setting the fixing device is very important. Even a small deviation can cause deformations, which in many cases are larger than in other types of quenching. A major disadvantage is the already mentioned uneconomics for parts with a high annual requirement.

The opposite case occurred during heat treatment on a continuous line. Such quenched parts showed high values of deformations. The ovality was several times higher than the values measured before quenching. The hardness analysis did not show any deviations from the prescribed values. The microstructure of the continuous quenching sample was also composed of martensite, carbides and residual austenite, but had a greater through-hardening than the rotary quenching sample. 
To compare the values measured after quenching in a continuous manner, a simulation was performed on the simulation software SYSWELD. The simulation confirmed the deformations created in a continuous way. By comparing the values, the largest deformation was found in the place with the smallest cross-section. This simulation can be used as a basis for designing technological processes of heat treatment, its task is to capture potential shortcomings of technology in a timely manner and minimize them or eliminate them in advance.

\section{Acknowledgement}

The article was made under support grant project KEGA 011ŽU-4/2020 Implementation of online education in the field of bearing technology with an emphasis on the educational process for improving the skills and flexibility of engineering technology students.

\section{References}

[1] GOCH, G. (2003) Gear Metrology. In: Annals of the CIRP, 52/2, pp. 659-695. Netherlands. ISSN 0007-8506

[2] BEEKHUISA, B., STOEBENERB, D., BRINKSMEIERA, E. (2012) Adapted NonCircular Soft Turning of Bearing rings - Impact of process machine interactions on compensation potential. In: Procedia CIRP, Vol. 1, pp. 540-545. Netherlands. ISSN 2212-8271

[3] KREJCI, L., SCHINDLEROVA, V., BUCKO, M., HLAVATY, I., MICIAN, M. (2019) The Application of PFMEA for Roller Bearings Production. In. Manufacturing Technology, 19(3), pp. 439-445. ISSN 1213-2489

[4] JECH, J. (1983) Heat treatment of steels Metallographic handbook. 4. vyd. Prague: SNTL, $392 \mathrm{p}$.

[5] KALINCOVÁ, D., ŤTAVODOVÁ, M., JAKUBÉCZYOVÁ, D. (2018) Quality evaluation of the coatings and its influence on the wood machining tool wear. In. Manufacturing Technology, 18(4), pp. 578-584. ISSN 12132489

[6] CARACH, J., HLOCH, S., PETRU, J., MUlLER, M., HROMASOVA, M., NAG, A., CUHA, D., HLAVACEK, P., HATALA, M., KRATOCHVIL, J., RUGGIERO, A. (2019) Evaluation of physical phenomena and surface integrity during hydroabrasive disintegration of the rotating workpiece with feedback loop control. In. Measurement. 134. pp. 586-594. England. ISSN 0263-2241

[7] SULKA, P., SAPIETOVA, A., DEKYS, V., SAPIETA, M. (2019) Comparison of analytical and numerical solution of bearing contact analysis. In. XXIII Polish-Slovak Scientific Conference on Machine Modelling And Simulations (MMS 2018) MATEC Web of Conferences. Vol. 254. Article Number: 02022

[8] EPP, J., SURM, H., HIRSCH, T., HOFFMANN, F. (2011) Residual stress relaxation during heating of bearing rings produced in two different manufacturing chains. In. Journal of Materials Processing Technology, Vol. 211, pp. 637-643. Switzerland. ISSN 09240136

[9] ROSSINI, N.S., DASSISTI, M., BENYOUNIS, K.Y., OLABI, A.G. (2012) Methods of measuring residual stresses in components. In: Materials and Design, Vol. 35, pp. 572-588

[10] BHADESHIA, H.K.D.H. (2012) Steels for bearings. In. Progress in Materials Science. No. 57, pp. 268-435. England. ISSN 0079-6425

[11] CSEH, D., BENKE, M., MERTINGER, V., CZIBIK, A. (2014) Residual Stress Evolution during the Manufacturing Process of Bearing Rings. In. Advanced Materials Research. Vol. 996, pp 664-669. Switzerland. ISSN 16628985

[12] BREZNIČAN, M. (2011) Modeling and optimization of the hardening process of bearing rings with regard to their deformations. Dissertation project. Žilina

[13] KRAUS, P., NÁPRSTKOVÁ, N. , JIROUNKOVÁ, K., CAIS, J., SVOBODOVÁ, J. (2018) Effect of heat treatment on the microstructure of the alloy AlSi7CrMnCu. In. Manufacturing Technology, 18(6), pp. 935-942. ISSN 1213-2489

[14] ESI GROUP (2003) SYSWELD for Heat Treatment. Virtual Manufacturing

[15] MORAVEC, J. (2009) Simulation of fusion welding - simulation program SYSWELD In. Zvárać, VI/2, pp. 9-12, ISSN 1336-5045 